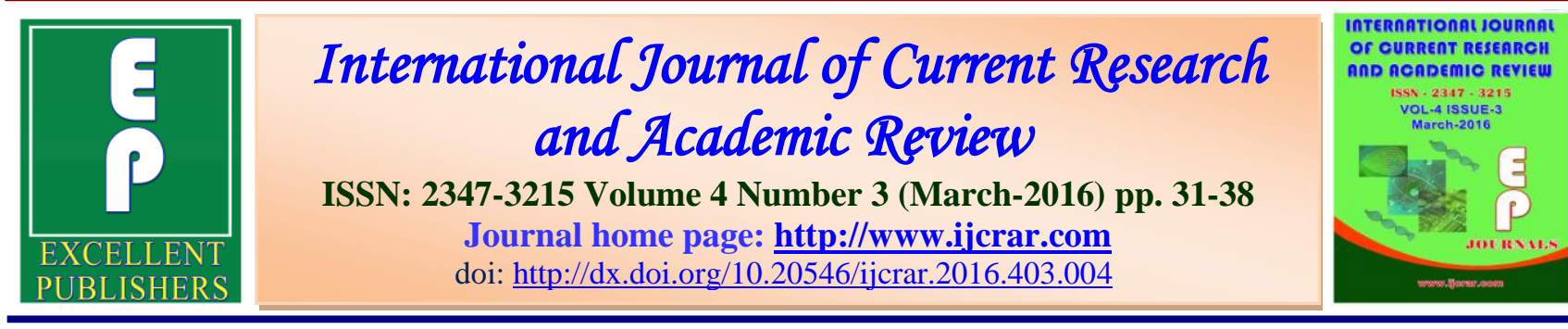

\title{
Effect of Zinc Supplementation on Glycemic Control and Electrophysiological Recording (ESP. Brainstem Auditory Evoked Potential) in Diabetic Patients (NIDDM) with Neuropathy
}

\author{
P.K. Maheshwari, Agrawal Prabhat*, Singh Akhilesh Kumar, Rajasekaran Govindan, \\ Upadhyay Shalini
}

Department of Medicine, S.N.Medical College, Agra, India

*Corresponding author

\begin{tabular}{|l|l|}
\hline \multirow{2}{*}{$\begin{array}{l}\text { KEYWO supplementation, } \\
\text { Glycemic control, } \\
\text { Electrophysiological } \\
\text { recording, }\end{array}$} & $\begin{array}{l}\text { A B S T R A C T } \\
\text { Diabetic patients, } \\
\text { and mortality in patients and neuropathy is one of its complication. Our study } \\
\text { is to study the effect of zinc supplementation on glycemic control and } \\
\text { electrophysiological recording (brainstem auditory evoked potential) in type } 2 \\
\text { diabetic patient with neuropathy. This study was carried out in the } \\
\text { Department of Medicine, S.N. Medical College and Associated Hospitals }\end{array}$ \\
$\begin{array}{l}\text { Agra from july2013 to January 2015. Type 2 diabetic patients with } \\
\text { Neuropathy receiving oral ZINC supplementation, metformin and gabapentin } \\
\text { therapy served as cases \& Diabetic Neuropathy patients of comparable age \& } \\
\text { sex receiving only metformin and gabapentin therapy served as control. All } \\
\text { patients were thoroughly examined and investigated for Fasting Blood Sugar, } \\
\text { HbA1c, S. Zinc at 0, 4, 8 and 16 week, similarly baseline BEP was done in all } \\
\text { patients. Serum Zinc levels were lower in Patients of Diabetic } \\
\text { Polyneuropathy. Effect of Zinc supplementation on fasting blood glucose was } \\
\text { extremely significant. Percentage change over baseline was 10.66\% as } \\
\text { compared to 7.58\% in those not supplemented with zinc, similary Results for } \\
\text { latency of BEAR of both ears were significant . }\end{array}$ \\
\hline
\end{tabular}

\section{Introduction}

Diabetes Mellitus and its complication still account for much of the morbidity and mortality in patients inspite of availability of various forms of effective treatment modalities.
Neuropathy, a common complication of diabetes mellitus, is generally considered to be related to duration and severity of hyperglycemia. Usually more than $50 \%$ of patients with duration of diabetes of 25 
years or more are affected, making it as one of the most common disease of the nervous system. One of the largest published series reported that prevalence of neuropathy is $7.5 \%$ even at the time of diagnosis of type 2 DM (Ashok et al., 2002).

Our study is to study the effect of zinc supplementation on glycemic control and electrophysiological recording (Bayazit et al., 2000) (brainstem auditory evoked potential) in type 2 diabetic patient with neuropathy. Diabetes affects zinc homeostasis in many ways, although it is most probably the hyperglycemia, rather than any primary lesion related to diabetes, which is responsible for the increased urinary loss (Cunningham et al., 1994) and decreases in total body zinc (Arquilla et al., 1978). Zinc plays a key role in the synthesis and action of insulin, both physiologically and in the pathologic state of diabetes (Raz et al., 1989). Hyperglycemia from either Type 1 or Type 2 diabetes causes physiologically important losses of $\mathrm{Zn}$ from the body. These losses may worsen the underlying diabetes but are probably not responsible as the causal agent. The complications of diabetes may be mediated, at least in part, through oxidative stress and $\mathrm{Zn}$ plays a key role in the cellular antioxidative defence. Jayawardena $R$, Ranasinghe $P$ et al demonstrated that Zinc supplementation shows beneficial effects on glycaemic control and promotes healthy lipid parameters (Jayawardena et al., 2012).

\section{Materials and Methods}

This study was carried out in the Department of Medicine, S.N. Medical College and Associated Hospitals Agra, over a period of I8 months from July 2013 to January 2015.
The objectives of our study were to study the co-relation between serum zinc level, blood glucose level and auditory evoked potential in diabetic patients with neuropathy, to study the effect of zinc supplementation on blood glucose level and auditory evoked potential in diabetic patients with neuropathy, to assess the value of auditory evoked potential alterations in predicting the stability and severity of auditory pathway disease related to diabetes. For our study 60 Type 2 diabetic patients who were suffering with Neuropathy from out door of Neurology unit receiving oral ZINC supplementation, metformin and gabapentin therapy served as cases \& 60 Diabetic Neuropathy patients of comparable age \& sex receiving only metformin and gabapentin therapy served as control. All patients underwent a detailed Neurologic examination. Patients were required to have at least two of the following:

1. Symptoms of Paraesthesia or Dysesthesia.

2. Reduced Vibratory sense below the Knee.

3. Reduced Ankle jerk compared to Knee jerk.

4. Reduced Discrimination and Light Touch sense distally in the Legs.

Exclusion criterias were Patients of diabetes mellitus with altered sensorium or disturbed mental state, having any other diseases known to cause peripheral neuropathy like chronic renal failure, liver failure, hypothyroidism, leprosy, porphyria etc. or on drugs known to cause peripheral neuropathy like isoniazid, phenytoin and Patients showing abnormal levels of blood urea, S. creatinine, abnormal liver function tests. 
All patients were thoroughly examined and investigated for Fasting Blood Sugar, HbA1c, S. Zinc, Blood urea and serum creatinine at first visit (0 weeks) and subsequently these tests were repeated at 4, 8,16 weeks respectively. Baseline BEP was done in all patients and Parameters measured were:

\section{Absolute latency and amplitude}

2. Interpeak latencies(IPL)

3. Amplitude ratio of wave $\mathrm{V} / \mathrm{I}$ or $\mathrm{IV}-\mathrm{V}$ complex

\section{Inter ear interpeak differences}

For evaluating the level of improvements in the Brainstem Evoked Potential, Cases (GROUP I) were given zinc supplementation (zinc chloride tablets) in the doses of $550 \mathrm{mg} / \mathrm{d}$ along with metformin and gabapentin drug for a period of 16 weeks and controls (GROUP II) were given only metformin and gabapentin for a period of 16 weeks. They were not given any zinc supplementation. Metabolic control was evaluated by the mean level of HbA1c \% measured in a sample of venous blood.

\section{Results and Discussion}

In our study total of 120 Patients were examined \& investigated. Patients were distributed according to different age starting from $>40$ years and according to sex. In group I maximum number of patients $(n=37)$ were in 50-60 age years and in group II maximum number of patients $(n=30)$ were in age group 50-60 years. In both group maximum number of patients were in 50-60 years age group. In group I there were 49 male patients and 11 female patients (M:F ratio 4.45:1) and in group II there were 47 males and 13 females (M:F ratio3.6:1). In both group males are affected more than females. Similar findings were observed by Pradeepa et al., (2008).

Average age of males was $56.53 \pm 0.6$ years and of females was 52.54 \pm 1.19 years in group I. In group II Average age of males was $54.7 \pm 0.84$ years and of females was $55.84+1.62$.

In present study mean serum zinc level in group I before treatment (i.e first visit) was $69.17 \pm 0.952 \mathrm{mg} / \mathrm{dl}$ as compared to after treatment values (16 weeks) 80.72+0.987 $\mathrm{mg} / \mathrm{dl}$. This difference was considered statistically significant $(\mathrm{p}<0.001)$.

In group II before treatment (i.e first visit) values of Mean Serum Zinc level was $69.43 \pm 2.165 \mathrm{mg} / \mathrm{dl}$ as compared to after treatment (i.e after 16 weeks) 62.48 \pm 2.122 $\mathrm{mg} / \mathrm{dl}$. This difference was statistically insignificant.

In present study values for Mean fasting blood glucose level in group I before treatment (i.e first visit) was 144.32 \pm 0.94 $\mathrm{mg} / \mathrm{dl}$ as compared to $128.93 \pm 0.75 \mathrm{mg} / \mathrm{dl}$ after treatment. This difference was considered extremely significant $(\mathrm{p}<0.001)$.

In group II values for mean fasting blood glucose level before treatment (i.e first visit) was $145.20 \pm 1.12 \mathrm{mg} / \mathrm{dl}$ as compared to $140.18 \pm 0.94 \mathrm{mg} / \mathrm{dl}$ values of fasting blood glucose after treatment. This Difference was considered non significant $(\mathrm{p}>0.001)$.

\section{Effect of zinc Supplementation on latency of Brainstem Evoked Potential}

In present study, values for Mean latency (in $\mathrm{ms}$ ) of BAEP in right ear in group I before

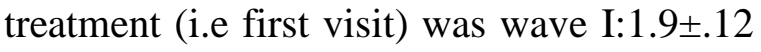
wave III:4.45 \pm .22 wave V:6.54 \pm .35 wave I-

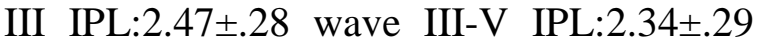
wave I-V IPL:4.41 \pm .36 compared to wave 
I: $1.61 \pm .08$ wave III:3.71 \pm .19 wave V:5.76 \pm .32 wave I-III IPL:2.11 \pm .25 wave III-V IPL: $2.0 \pm .25$ wave I-V IPL:4.16 \pm .23 respectively after treatment. This difference was considered extremely significant after treatment in right ear.

In group II before treatment (i.e first visit) was wave I: $1.86 \pm .14$ wave III:4.46 \pm .17 wave V:6.49 .31 wave I-III IPL:2.53 \pm .32 wave III-V IPL:2.31 \pm .27 wave I-V IPL:4.42 \pm .21 compared to wave I:1.87 \pm .18 wave III:4.38 \pm 1.8 wave V:6.6 \pm .28 wave IIII IPL:2.61 \pm .28 wave III-V IPL:2.5 \pm .29 wave I-V IPL:4.58 \pm .22 respectively after treatment. This difference was considered not significant after treatment in right ear.

In present study values for Mean latency (in $\mathrm{ms}$ ) of BAEP in left ear in group I before treatment (i.e first visit) was wave I:1.8 \pm .13 wave III: $4.46 \pm .24$ wave V:6.5 \pm .33 wave I-

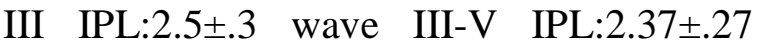
wave I-V IPL:4.4 \pm .38 compared to wave I: $1.64 \pm .05$ wave III:3.75 \pm .20 wave

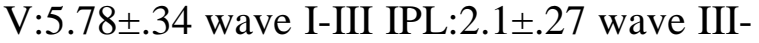

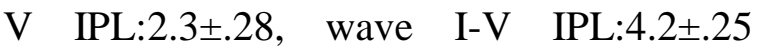
respectively after treatment. This difference was considered significant after treatment in left ear.

Table.1 Average Age in Years (Mean \pm S.E.M.) in Both Sexes in Different Groups Different Groups

\begin{tabular}{|l|l|l|}
\hline \multicolumn{1}{|c|}{ SEX } & \multicolumn{1}{|c|}{ GROUP-I } & \multicolumn{1}{c|}{ GROUP-II } \\
\hline MALE & $56.53 \pm 0.6573$ & $54.70 \pm 0.847$ \\
& $(\mathrm{n}=49)$ & $(\mathrm{n}=47)$ \\
& S.D $=4.60$ & S.D $=5.82$ \\
\hline FEMALE & $52.54 \pm 1.19$ & $55.84 \pm 1.62$ \\
& $(\mathrm{n}=11)$ & $(\mathrm{n}=13)$ \\
& S.D $=3.96$ & S.D $=5.86$ \\
\hline TOTAL & $55.8 \pm 0.6096$ & $54.95 \pm 0.7476$ \\
& $(\mathrm{n}=60)$ & $(\mathrm{n}=60)$ \\
& S.D $=4.722$ & S.D $=5.791$ \\
\hline
\end{tabular}

Table.2 Serum Zinc (mg/dl) Before and After Treatment

\begin{tabular}{|c|c|c|c|c|c|c|c|c|}
\hline & \multicolumn{4}{|c|}{ GROUP I (n=60) } & \multicolumn{4}{|c|}{ GROUP II $(n=60)$} \\
\hline & \multirow{2}{*}{$\begin{array}{l}\text { Before } \\
\text { treatment }\end{array}$} & \multicolumn{3}{|c|}{ After Treatment } & \multirow{2}{*}{$\begin{array}{l}\text { Before } \\
\text { treatment }\end{array}$} & \multicolumn{3}{|c|}{ After Treatment } \\
\hline & & 4 weeks & 8 weeks & 16 weeks & & 4 weeks & 8 weeks & 16 weeks \\
\hline Mean & 69.17 & 71.07 & 74.67 & 80.72 & 69.43 & 68.07 & 65.62 & 62.48 \\
\hline S.D & 7.38 & 7.29 & 7.21 & 7.65 & 16.77 & 16.67 & 16.49 & 16.44 \\
\hline S.E.M & 0.952 & 0.941 & 0.930 & 0.987 & 2.165 & 2.153 & 2.129 & 2.122 \\
\hline $\begin{array}{l}\text { \% Change Over } \\
\text { Baseline }\end{array}$ & & & & 16.7 & & & & 19.9 \\
\hline p Value & & & & $\mathrm{P}<0.001$ & & & & $P>0.05$ \\
\hline
\end{tabular}


Int.J.Curr.Res.Aca.Rev.2016; 4(3): 31-38

Table.3 Fasting Blood Glucose (Mg/Dl) Before and After Treatment

\begin{tabular}{|c|c|c|c|c|c|c|c|c|}
\hline & \multicolumn{4}{|c|}{ GROUP I $(n=60)$} & \multicolumn{4}{|c|}{ GROUP II $(\mathrm{n}=60)$} \\
\hline & \multirow{2}{*}{$\begin{array}{c}\text { Before } \\
\text { treatment }\end{array}$} & \multicolumn{3}{|c|}{ After Treatment } & \multirow{2}{*}{$\begin{array}{c}\text { Before } \\
\text { treatment }\end{array}$} & \multicolumn{3}{|c|}{ After Treatment } \\
\hline & & 4 weeks & 8 weeks & 16 weeks & & 4 weeks & 8 weeks & 16 weeks \\
\hline Mean & 144.32 & 140.70 & 134.81 & 128.93 & 145.20 & 142.23 & 138.40 & 140.18 \\
\hline S.D & 7.28 & 6.79 & 6.51 & 5.82 & 8.68 & 8.14 & 7.87 & 7.30 \\
\hline S.E.M & 0.94 & 0.87 & 0.84 & 0.75 & 1.12 & 1.05 & 1.01 & 0.94 \\
\hline $\begin{array}{l}\text { \% Change Over } \\
\text { Baseline }\end{array}$ & & & & -10.66 & & & & -7.58 \\
\hline $\mathrm{p}$ Value & & & & $\mathrm{P}<0.001$ & & & & $\mathrm{P}>0.001$ \\
\hline
\end{tabular}

Table.4 Latency (Ms) of Waves in B.A.E.P of Right Ear Before and After Treatment

\begin{tabular}{|l|l|c|c|c|c|c|c|c|}
\hline Wave & $\begin{array}{l}\text { Cases (60) } \\
\text { Before } \\
\text { treatment }\end{array}$ & $\begin{array}{c}\text { After } \\
\text { treatment }\end{array}$ & & \multicolumn{2}{|c|}{$\begin{array}{l}\text { Controls(60) } \\
\text { Before } \\
\text { treatment }\end{array}$} & $\begin{array}{l}\text { After } \\
\text { treatment }\end{array}$ & & \\
\cline { 3 - 9 } & & 4 week & 8 week & 16 week & At 1st visit & 4week & 8 week & 16 week \\
\hline I & $1.9 \pm .12$ & $1.82 \pm .09$ & $1.75 \pm .1$ & $1.61 \pm .08$ & $1.86 \pm .14$ & $1.88 \pm .15$ & $1.84 \pm .16$ & $1.87 \pm .18$ \\
\hline III & $4.45 \pm .22$ & $4.11 \pm .24$ & $3.96 \pm .22$ & $3.71 \pm .19$ & $4.36 \pm .17$ & $4.4 \pm .21$ & $4.53 \pm .1 .6$ & $4.38 \pm 1.8$ \\
\hline V & $6.54 \pm .35$ & $6.18 \pm .32$ & $5.92 \pm .33$ & $5.76 \pm .32$ & $6.49 \pm .31$ & $6.53 \pm .28$ & $6.50 \pm .29$ & $6.6 \pm .28$ \\
\hline $\begin{array}{l}\text { I-III } \\
\text { IPL }\end{array}$ & $2.47 \pm .28$ & $2.41 \pm .26$ & $2.22 \pm .24$ & $2.11 \pm .25$ & $2.53 \pm .32$ & $2.58 \pm .29$ & $2.54 \pm .30$ & $2.61 \pm .28$ \\
\hline $\begin{array}{l}\text { III-V } \\
\text { IPL }\end{array}$ & $2.34 \pm .29$ & $2.23 \pm .31$ & $2.12 \pm .28$ & $2.0 \pm .25$ & $2.51 \pm .27$ & $2.44 \pm .31$ & $2.48 \pm .30$ & $2.5 \pm .29$ \\
\hline $\begin{array}{l}\text { I-V } \\
\text { IPL }\end{array}$ & $4.41 \pm .36$ & $4.34 \pm .32$ & $4.23 \pm .27$ & $4.16 \pm .23$ & $4.62 \pm .21$ & $4.53 \pm .24$ & $4.59 \pm .25$ & $4.58 \pm .22$ \\
\hline
\end{tabular}

For Cases

\begin{tabular}{|l|l|l|l|}
\hline & At week 1 Cases & At week 16 Cases & P value \\
\hline I & $1.9 \pm .12$ & $1.61 \pm .08$ & $<0.0001$ \\
\hline III & $4.45 \pm .22$ & $3.71 \pm .19$ & $<0.0001$ \\
\hline V & $6.54 \pm .35$ & $5.76 \pm .32$ & $<0.0001$ \\
\hline I-III & $2.47 \pm .28$ & $2.11 \pm .25$ & $<0.0001$ \\
\hline III-V & $2.34 \pm .29$ & $2.0 \pm .25$ & $<0.0001$ \\
\hline I-V & $4.41 \pm .36$ & $4.16 \pm .23$ & $<0.0001$ \\
\hline
\end{tabular}

For Control

\begin{tabular}{|l|l|l|l|}
\hline & At week 1 Control & At week 16 Control & P value \\
\hline I & $1.86 \pm .14$ & $1.87 \pm .18$ & $0.08(>0.0001)$ \\
\hline III & $4.46 \pm .17$ & $4.38 \pm 1.8$ & $0.021(>0.0001)$ \\
\hline V & $6.49 \pm .31$ & $6.6 \pm .28$ & $0.0035(>0.0001)$ \\
\hline I-III & $2.53 \pm .32$ & $2.61 \pm .28$ & $0.031(>0.0001)$ \\
\hline III-V & $2.31 \pm .27$ & $2.5 \pm .29$ & $0.06(>0.0001)$ \\
\hline I-V & $4.42 \pm .21$ & $4.58 \pm .22$ & $<0.0001$ \\
\hline
\end{tabular}


Int.J.Curr.Res.Aca.Rev.2016; 4(3): 31-38

Table.5 Latency (Ms) of Waves in B.A.E.P of Left Ear Before and After Treatment

\begin{tabular}{|c|c|c|c|c|c|c|c|c|}
\hline \multirow[t]{3}{*}{ Wave } & \multicolumn{4}{|l|}{ Cases (60) } & \multirow{2}{*}{\multicolumn{4}{|c|}{ Controls(60) }} \\
\hline & \multirow{2}{*}{$\begin{array}{l}\text { Before } \\
\text { treatment }\end{array}$} & \multicolumn{3}{|c|}{ After treatment } & & & & \\
\hline & & 4weak & 8 weak & 16 weak & $\begin{array}{l}\text { At } 1^{\text {st }} \\
\text { visit }\end{array}$ & 4weak & 8 weak & 16 weak \\
\hline $\mathrm{I}$ & $1.8 \pm .13$ & $1.7 \pm .1$ & $1.8 \pm .1$ & $1.64 \pm .05$ & $1.82 \pm .13$ & $1.9 \pm .14$ & $1.86 \pm .15$ & $1.86 \pm .16$ \\
\hline II & & & & & & & & \\
\hline III & $4.46 \pm .24$ & $4.1 \pm .22$ & $3.98 \pm .21$ & $3.75 \pm .20$ & $4.37 \pm .18$ & $4.3 \pm .2$ & $4.52 \pm .1 .7$ & $4.28 \pm 1.7$ \\
\hline IV & & & & & & & & \\
\hline $\mathrm{V}$ & $6.5 \pm .33$ & $6.1 \pm .3$ & $5.9 \pm .31$ & $5.78 \pm .34$ & $6.5 \pm .3$ & $6.61 \pm .30$ & $6.5 \pm .3$ & $6.61 \pm .29$ \\
\hline VI & & & & & & & & \\
\hline $\begin{array}{l}\text { I-III } \\
\text { IPL }\end{array}$ & $2.5 \pm .3$ & $2.3 \pm .23$ & $2.24 \pm .27$ & $2.1 \pm .27$ & $2.5 \pm .31$ & $2.56 \pm .28$ & $2.55 \pm .28$ & $2.63 \pm .29$ \\
\hline $\begin{array}{l}\text { III-V } \\
\text { IPL }\end{array}$ & $2.37 \pm .27$ & $2.3 \pm .3$ & $2.15 \pm .25$ & $2.3 \pm .28$ & $2.5 \pm .29$ & $2.40 \pm .3$ & $2.46 \pm .29$ & $2.53 \pm .30$ \\
\hline $\begin{array}{l}\text { III-V } \\
\text { IPL }\end{array}$ & $2.37 \pm .27$ & $2.3 \pm .3$ & $2.15 \pm .25$ & $2.3 \pm .28$ & $2.5 \pm .29$ & $2.40 \pm .3$ & $2.46 \pm .29$ & $2.53 \pm .30$ \\
\hline $\begin{array}{l}\text { I-V } \\
\text { IPL }\end{array}$ & $4.4 \pm .38$ & $4.3 \pm .26$ & $4.26 \pm .25$ & $4.2 \pm .25$ & $4.6 \pm .22$ & $4.5 \pm .34$ & $4.60 \pm .27$ & $4.58 \pm .22$ \\
\hline
\end{tabular}

For Cases

\begin{tabular}{|l|l|l|l|}
\hline & At week 1 Cases & At week 16 Cases & P value \\
\hline I & $1.8 \pm .13$ & $1.64 \pm .05$ & $<0.0001$ \\
\hline III & $4.46 \pm .24$ & $3.75 \pm .20$ & $<0.0001$ \\
\hline V & $6.5 \pm .33$ & $5.78 \pm .34$ & $<0.0001$ \\
\hline I-III & $2.5 \pm .3$ & $2.1 \pm .27$ & $<0.0001$ \\
\hline III-V & $2.37 \pm .27$ & $2.3 \pm .28$ & $<0.0001$ \\
\hline I-V & $4.4 \pm .38$ & $4.2 \pm .25$ & $<0.0001$ \\
\hline
\end{tabular}

For Controls

\begin{tabular}{|l|l|l|l|}
\hline & At week 1 Control & At week 16 Control & P value \\
\hline I & $1.82 \pm .13$ & $1.86 \pm .16$ & $0.0051(>0.0001)$ \\
\hline III & $4.37 \pm .18$ & $4.28 \pm 1.7$ & $0.0007(>0.0001)$ \\
\hline V & $6.5 \pm .3$ & $6.61 \pm .29$ & $0.006(>0.0001)$ \\
\hline I-III & $2.5 \pm .31$ & $2.63 \pm .29$ & $0.034(>0.0001)$ \\
\hline III-V & $2.5 \pm .29$ & $2.53 \pm .30$ & $0.02(>0.0001)$ \\
\hline I-V & $4.6 \pm .22$ & $4.5 \pm .22$ & $0.008(>0.0001)$ \\
\hline
\end{tabular}

In group II before treatment (i.e first visit) was wave I: $1.82 \pm .13$, wave III:4.37 \pm .18 , wave V:6.5 \pm .3 , wave I-III IPL:2.5 \pm .31 , wave III-V IPL:2.5 \pm .29 , wave I-V IPL:4.6 \pm .22 compared to wave I: $1.86 \pm .16$, wave III: $4.28 \pm 1.7$, wave V:6.61 \pm .29 , wave
I-III IPL: $2.63 \pm .29$, wave III-V IPL:2.53 \pm .30 , wave I-V IPL: $4.58 \pm .22$ respectively after treatment. This difference was considered insignificant after treatment in left ear. 
Diabetes is the leading known cause of neuropathy in the world. Neuropathy is the most common complication and greatest source of morbidity and mortality in diabetic patients. It is estimated that the prevalence of neuropathy in diabetes patients is approximately 20\% (Maser et al., 1989). Zinc is known to be necessary for achieving better glycemic control and improvement in peripheral neuropathy as assessed by motor nerve conduction velocity (Hayee et al., 2005). Diabetics affects zinc metabolism in many ways McNair et al confirmed hyperzincuria in relationship to the degree of hyperglycaemia (McNair et al., 1981). Kinlaw et al demonstrated abnormal $\mathrm{Zn}$ tolerance test in diabetic patients suggestive of decreased absorption (Kinlaw et al., 1983). Al-Maroof RA, Al-Sharbatti SS showed that Diabetic patients have significantly lower mean serum zinc levels compared with healthy controls (Al-Maroof and Al Sharbatti). Our study showed that

Serum Zinc levels were lower in Patients of Diabetic Polyneuropathy in both the groups.

In Group I Effect of Zinc supplementation on fasting blood glucose was extremely significant. In Group II results were not significant. Percentage change over baseline in group I was $10.66 \%$ as compared to $7.58 \%$ in group II.

Results for latency of BEAR of both ears were significant in group I. Results were insignificant in group II.

For prevention of diabetes mellitus/or its complications it is essential to know the pathogenesis of disease as well various factors which modify the course of disease and its complications in this regard. Present study was conducted to evaluate whether or not Zinc supplementation helps to restore blood glucose level and helps to improve amplitude and latency of BAER in patients of diabetic neuropathy.

\section{References}

Ashok, S., Ramu, M., Deepa, R., Mohan, V. 2002. Prevalence of neuropathy in type 2 diabetic patients attending a diabetes centre in South India. J. Assoc. Physicians India, 50: 546-50.

Bayazit, Y., Yilmaz, M., Kepekgi, Y., Mumbuc, S., Kanlikama, M. 2000. Use of the auditory brainstem response testing in the clinical evaluation of the patients with diabetes mellitus. $J$. Neurol. Sci., 181(1-2): 29-32.

Cunningham, J., Fu, A., Mearkle, P., Brown, R. 1994. Hyperzincuria in individuals with insulin dependent diabetes mellitus: concurrent zinc status and the effect of high dose zinc supplementation. Metabolism, 43: 1581562.

Arquilla, E.R., Packer, S., Tarmas, W., Miyamoto, S. 1978. The effect of zinc on insulin metabolism. Endocrinol., 103: 1330-1449.

Raz, I., Karsai, D., Katz, M. 1989. The influence of zinc supplementation on glucosehomeostasis in NIDDM. Diabetes Res., 11: 73-79.

Jayawardena, R., Ranasinghe, P., Galappatthy, P., et al. 2012. Effects of zinc supplementation on diabetes mellitus: a systematic review and metaanalysis. Diabetol. Metabolic Syndrome, 4: 13.

Pradeepa, R., Rema, M., Vignesh, J., Deepa, M., Deepa, R., Mohan, V. 2008. Prevalence and risk factors for diabetic neuropathy in an urban south Indian population: the Chennai Urban Rural Epidemiology Study (CURES-55). Volume 25, Issue 4, pp. 407-412. 
Maser, R.E., Steenkiste, A.R., Dorman, J.S. et al. 1989. Epidemiological correlates of diabetic neuropathy. Report from Pittsburgh Epidemiology of Diabetes Complications Study. Diabetes, 38: 1456.

Hayee, M.A., Mohammad, Q.D., Haque, A. 2005. Diabetic neuropathy and zinc therapy. Bangladesh Med. Res. Counc. Bull., 31(2): 62-7.

McNair, P., Kiilerich, S., Christiansen, C., Christiansen, M., Madsbad, S., Transbol, I. 1981. Hyperzincuria in insulin treated diabetes mellitus-its relation to glucose homeostasis and insulin administration. Clinica Chimica Acta, 112: 343-348.

Kinlaw, W.B., Levine, S., Morley, J., Silvis, S., McClain, C. 1983. Abnormal zn metabolism in type II diabetes mellitus. Am. J. Med., 75: 273-277.

Al-Maroof, A., Al Sharbatti, S.S. Serum zinc levels in diabetic patients and effect of zinc supplementation on glycemic control of type 2 diabetics. Ministry of Health Baghdad, Iraq. PMID: 16532095.

\section{How to cite this article:}

P.K. Maheshwari, Agrawal Prabhat, Singh Akhilesh Kumar, Rajasekaran Govindan, Upadhyay Shalini. 2016. Effect of Zinc Supplementation on Glycemic Control and Electrophysiological Recording (ESP. Brainstem Auditory Evoked Potential) in Diabetic Patients (NIDDM) with Neuropathy. Int.J.Curr.Res.Aca.Rev.4(3): 31-38. doi: http://dx.doi.org/10.20546/ijcrar.2016.403.004 